\title{
Are Social Media Groups the Novel Physician Lounges to Combat COVID Times?
}

\author{
Suman Shekar, $M D^{7}$ and Avinash Aravantagi, $M D^{2}$ \\ 'Medical Center Primary Care, University of Kentucky Bowling Green Campus, Bowling Green, KY, USA; ${ }^{2}$ Department of Gastroenterology, Graves \\ Gilbert Clinic, Bowling Green, KY, USA.
}

$\mathrm{J}$ Gen Intern Med 35(11):3355-6

DOI: $10.1007 / \mathrm{s} 11606-020-06217-\mathrm{y}$

(c) Society of General Internal Medicine 2020

$\mathrm{S}$ ocial media platforms are an increasingly dominant channel through which physicians encounter news in their everyday life. Social media sites such as Twitter, Instagram, YouTube, Facebook, and Snapchat are all powerful tools. Facebook is a platform wherein likeminded people can create groups to share their knowledge and to interact, making it a formidable force and voice. The purpose of this article is to understand the ubiquity of social media groups and their influence on physicians to treat patients with coronavirus disease 2019 [COVID-19].

In late December 2019, an outbreak of a mysterious pneumonia characterized by fever, dry cough, fatigue, and occasional gastrointestinal symptoms started in China and spread to many other countries. ${ }^{1}$ COVID-19 spread rapidly outside China and the number of affected countries, states, or territories reporting infections to WHO was 143 by March 16th $2020 .^{2}$

The challenge during the pandemic is the speed required to transfer the knowledge of current best practices to the physicians. It needs to be at a pace equal to or better than the spreading epidemic. The paths for, and rate of, dissemination of traditional peer review scholarly publications, static websites, and even emails are known to be slow. ${ }^{3}$ During the SARS epidemic in 2003, worldwide Internet access was well established, yet gaining access to potential medical users was largely reliant on email contact and personal communication.

In this era of public health emergency, preprint versions of the scholarly articles evolved just like social media groups to provide the speediest way to disseminate the information. Preprint versions of COVID-19 are immediately made available to the public similar to social media groups. A potential problem with preprint publications is that they are not peerreviewed. If the preprint undergoes changes during the peer review or fails to get published in the peer review journal, the

Received May 25, 2020

Accepted September 3, 2020

Published online September 16, 2020 originally submitted article will remain in the preprint server and can distort the literature. Although preprint publications and social media groups give open access to all physicians and healthcare workers, it needs to be taken with a grain of salt.

There are hundreds of Facebook public and private groups created by physicians for physicians to interact and provide expertise (Table 1). To give an example of the impact, there is a COVID-19 USA physician Facebook group with more than 150,000 members on a single platform irrespective of the specialties.

The discussions had a wide array of COVID-19 topics like clinical manifestations, testing, plasma donation, mental health resources, critical care management, and personal protection equipment [PPE]. The rationale to use potential medications like hydroxychloroquine, chloroquine, acetazolamide, nifedipine, phosphodiesterase inhibitors, and remdesivir were debated. Multiple videos were made by physicians about safe donning and doffing which was appreciated to be useful by most of the physicians.

Algorithms to reduce the impact of false-negative testing were discussed by many virologists. The neurologists spoke about encephalitis, Guillain-Barre syndrome-like presentation by the virus; hematologists spoke about RBC damaging link to thalassemia porphyria, sickle cell disease; and dermatologists discussed the manifestations of livedoid eruptions and petechiae, whereas psychiatrists discussed delirium and agitation in hospitalized patients. Many physician innovators educated their peers on the tricks of the trade.

Physicians also discussed minimizing risks and decreasing the spread to their families. There was a mega thread about how physicians needed to disinfect themselves before entering their houses. There were shared experiences of physicians who were burnt out working 12-h shifts taking care of exclusively COVID-19 patients. This platform gave strength and resilience to improve personal wellbeing.

As the COVID-19 pandemic played out on the East Coast, the physicians who were in the crux of the pandemic discussed each and every situation in detail to let the other physicians in the entire country know what is going on and what to be expected.

The methodology and algorithm used by infection control at the University of California San Francisco were available in the second week of March 2020 for guidance. This gave a heads up to the majority of the physicians who were 
Table 1 Names of Physician Groups in Facebook Platform with Approximate Members

\begin{tabular}{ll}
\hline \hline Physician groups & $\begin{array}{l}\text { Total } \\
\text { members }\end{array}$ \\
\hline COVID-19 USA physician/APP group & $>150,000$ \\
Physician Mom COVID-19 group & $>36,000$ \\
COVID-19 physician group & $>27,000$ \\
COVID-19 USA healthcare workers PPE subgroup group & $>7000$ \\
Community outbreaks COVID-19 group for & $>3000$ \\
physicians & $>107,280$ \\
COVID-19: Real talk from healthcare workers around the & $>15,000$ \\
globe & $>1700$ \\
COVID-19 dental discussion & $>3000$ \\
COVID-19 physicians memorial & $>1100$ \\
COVID-19 mental health support group & $>2000$ \\
NY physicians-COVID-19 & $>700$ \\
Clinical epidemiological discussion of COVID-19 pan- \\
demic group & $>1200$ \\
COVID-19 outpatient primary care physician group & $>900$ \\
COVID-19 Texas physicians at advanced practice & $>400$ \\
Resident and fellow's physician COVID-19 group & \\
COVID-19/coronavirus South Florida physician & \\
\hline
\end{tabular}

geographically located behind on the curve of the pandemic to know what to expect.

Shortly after the groups were created, physicians teamed up with a legal group to get their voices heard about the PPE to the US federal government. There is some movement to form a physician union on a national level: "COVID-19 pandemic physician protection plan," which is written by a group of physicians which encompasses all healthcare workers and discusses ideas regarding optimal use of PPE, contract protections, malpractice protections, physician family protection if disabled or death, student debts, tax credits, keeping the practices solvent, telehealth expansion, and mental health issues.

With all that being said, social media platforms do carry the burden of not being evidence-based. The expectation is to discuss evidence-based medicine and anecdotal cases in a professional, respectful, and non-confrontational way. Occasionally, there were opinions and trolls wherein the group admin intervention was needed. A recent study from China depicted a high prevalence of mental health problems, which positively associated with frequent social media exposure during the COVID-19 outbreak. "Infodemic" or an immense amount of information can lead to depression and anxiety among the group members.

In conclusion, physicians from different professional and personal backgrounds and different subspecialties came together for one cause, to beat the COVID-19 pandemic. Physicians who are taking care of real-time patients contribute and are a good educational resource during the time of this pandemic.

With these new technological advances and important lessons from social media groups, the physicians are confident and equipped to fight COVID-19. Moving forward, this platform hopefully will pave the way for the dissemination of evidence-based information efficiently and effectively not only for COVID-19 but also for all the other future clinical challenges.

Corresponding Author: Suman Shekar, MD; Medical Center Primary Care, University of Kentucky Bowling Green Campus, Bowling Green, KY, USA (e-mail: sheks@mchealth.net).

\section{Compliance with Ethical Standards:}

Conflict of Interest: The authors declare that they do not have a conflict of interest.

\section{REFERENCES}

1. Wu YC, Chen CS, Chan YJ. The outbreak of COVID-19: An overview. J Chin Med Assoc. 83(3):217-220. https://doi.org/10.1097/JCMA. 0000000000000270.

2. WHO report Coronavirus disease (COVID-2019) situation reports. Situation report-55 March 15th 2020.

3. Chan AKM, Nickson CP, Rudolph JW,Lee A, Joynt GM. Social media for rapid knowledge dissemination :early experience from COVID-19 Pandemic. Anesthesia. 2020;https://doi.org/10.1111/anae.15057.

4. Gao J, Zheng P, Jia Y, Chen H, Mao Y, Chen S, Dai J. Mental Health Problems and Social Media Exposure During COVID-19 Outbreak. PLoS One. 15(4): e0231924. https://doi.org/10.1371/journal.pone.0231924.

Publisher's Note: Springer Nature remains neutral with regard to jurisdictional claims in published maps and institutional affiliations. 